"This is the peer reviewed version of the following article:

Raitakari, Suvi, Haahtela, Riikka and Juhila, Kirsi (2016) Tackling Community Integration in Mental Health Home Visit Integration in Finland. Health and Social Care in the Community, which has been published in final form at 10.1111/hsc.12246. This article may be used for non-commercial purposes in accordance with Wiley Terms and Conditions for Self-Archiving."

\title{
Tackling community integration in mental health home visit integration in
}

\section{Finland}

\begin{abstract}
Integration - and its synonym inclusion -is emphasised in the Western welfare states and in the European Union in particular. Integration is also a central topic in social sciences and in current mental health and homelessness research and practice. As mental health care has shifted from psychiatric hospitals to the community, it has inevitably become involved with housing and integration issues. This article explores how community integration is understood and tackled in
\end{abstract} mental health floating support services (FSSs) and, more precisely, in service user-practitioner home visit interaction. The aim is to shed light on how the idea of integration is present and discussed in front-line mental health practices, and thus to offer a 'template' on how we might in a systematic and reflecting way develop community integration research and practice. The analysis is based on ethnomethodological and micro-sociological interaction research. The research settings are two FSSs located in a large Finnish city. The data contains 24 audio-recorded and transcribed home visits conducted in 2011 and 2012 with 16 different service users. The study shows how the participants in service user-practitioner interaction give meanings to community integration and make decisions about how it should (or should not) be enhanced in each individual case. This activity is called community integration work in action. Community integration work in action is based on various dimensions of integration: getting out of the house, participating in group activities and getting along with ones' close ones and involving in working life. Additionally the analysis demonstrates how community integration work is accomplished by discursive devices (resistance, positioning, excuses and justifications, delicacy and advice giving). The article concludes that community integration is 
about interaction, it is not only service users' individual challenge but also a social challenge, our challenge.

Key words: mental health, community integration, Housing First, recovery, interaction, ethnomethodology

\section{What is known about this topic?}

- Integration is high on the European Union's agenda.

- Community integration is emphasized in current mental health and homelessness research.

- Citizens with mental health difficulties report fairly low levels of community integration.

\section{What this paper adds:}

- The study approaches community integration as it is understood and tackled in service userpractitioner home visit interaction.

- The community integration work is based on various dimensions of integration and it is accomplished in interaction by discursive devices.

- Integration is to be understood broadly as both an individual and social challenge, our challenge.

\section{Introduction}

Integration - and its synonym inclusion - is a central topic in the Western welfare states, and in the European Union in particular (e.g. Musterd \& Alan 2002, European Commission Green Paper 2005, Abbott \& McConkey 2006, Hall 2010, Saunders 2013). Integration (or inclusion) is articulated in political discourse as a way to tackle social exclusion and to increase the citizens' participation and activity in the society. Integration has also been examined extensively in social sciences, mental health and homelessness research (Anthony 1993, Yanos et al. 2004, Farone 2006, Onken et al. 2007, 
Tsemberis 2010, Moriarty et al. 2012, Tsai et al. 2012, Cornes et al. 2014). In research it is often defined as active citizenship, connectedness and involvement in the community and services. Integration is presented as one key element in successful housing and recovery from sicknesses, disabilities and addictions (e.g. Kaplan et al. 2012; Ware et al. 2007, Farone 2006). The service users themselves are stressed as wanting integration and a normal life in the community (Beresford et al. 2005). Adopting valued social roles in the community is expected to produce such benefits as increasing life satisfaction, self-esteem, and personal competencies (Stein \& Wemmerus 2001, Aubry et al. 2013).

The social exclusion of citizens with disabilities is shown to be partly related to segregating service and housing solutions (Abbott \& McConkey 2006, Hall 2010, Stancliffe 2014). Hence there have been major political and service system changes toward better integration of disabled citizens (e.g. Carnaby et al. 2011, Stancliffe 2014). Accordingly the emphasis of mental health care has shifted from psychiatric hospitals and nursing homes to the community-based solutions (Ridgeway \& Zipple 1990, O’Hara 2007; Aubry et al. 2013: 219-220). Services based on supported housing and floating support have become more common and are intended to maximize opportunities for community integration (Carling 1990, Wong \& Solomon 2002, Yanos et al. 2011). Supported housing arranged in ordinary neighbourhoods and apartments that is scattered housing, is argued to enhance integration better than special, institutional housing solutions (e.g. Gulcur et al. 2007, Aubry et al. 2013). Yet many service users experience barriers in finding stable housing and a satisfying life in the community. Living in the community does not ensure belonging to the community (Ware et al. 2007).

In this article we explore how community integration is understood and tackled in mental health floating support services (FSSs) and more precisely in service user-practitioner home visit interaction. The aim is to shed light on how the idea of integration is present and discussed in front- 
line mental health practices, and thus to offer a 'template' on how we might in a systematic and reflecting way develop community integration research and practice. In the home visit interaction, integration is talked into being as concrete challenges that service users confront in their housing and engaging with communities and other citizens. Before describing in more detail the research design and results, we clarify integration as a research topic in social science, mental health and homelessness research. We concentrate especially on the Housing First (HF) and recovery literature that has become internationally influential in current homelessness and mental health research. The majority of studies on HF, recovery and integration are based on surveys, comparisons and firstperson accounts. To our knowledge there are no previous studies approaching integration as a phenomenon talked into being and tackled in service user-practitioner home visit interaction.

\section{Integration in social science, mental health and homelessness literature}

Integration is a fundamental topic in social sciences and traditionally it has been understood as a nostalgic 'wholeness' of the society (national states) and as cohesion (Cameron 2006, Loch 2014). Integration discourse gets its fuel from the ever present risk of fragmented and individualized society; from the possibility that citizens are drifting away from the 'mainstream' to be 'outsiders' at the margins (Cameron 2006, Schinkel 2013, Loch 2014). Integration discourse gives vocabularies to construct and make sense of 'otherness' related for example to poverty, living in poor neighbourhoods and lack of opportunities, choices and good health. 'Otherness' is associated to such social groups as immigrants, young people, homeless, social benefit receivers, long-term unemployed, lone parents, physically, intellectually and/or mentally disabled citizens ( (Hall 2010). These groups are commonly constructed as in need of integration measures. 
Integration discourse has also been criticized for its normative and individualistic tones (Cameron 2006, Hall 2010, Saunders 2013, Wieviorka 2014). It is argued to produce a 'discourse of exception', 'discourse of domination', and being an exercise of 'normative boundary setting' (Cameron 2006, Wieviorka 2014). Often integration is represented as a demand and a duty of the vulnerable citizens, consequently undermining its structural and social dimensions. In political and public debates integration easily narrows to claims to engage in work life and other ways to integrate are not recognized or valued (Hall 2010). However, these critical views are not very much present in current homelessness and mental health research but positive aspects of promoting vulnerable citizens' integration and recovery are emphasized.

Common, yet limited way to conceptualize integration is to divide it to physical, social and psychological dimensions (e.g. Abdallah et al. 2009, Wong \& Solomon 2002; Nemiroff et al. 2011, Aubry et al. 2013). Physical integration refers to participation in local activities and services whereas social integration refers to interaction among community members. Psychological dimension is related to belonging and a sense of community (Yanos et al. 2011).

The Housing First (HF) model was developed by the Pathways to Housing organization in the United States in the early 1990s, and during the last ten years it has been applied and developed in many Western countries (Pleace 2012, Pleace \& Bretherton 2012). The core argument of HF is that homeless people with severe mental difficulties and addictions are able to live in scattered housing and in ordinary communities if intensive support is available (Tsemberis \& Eisenberg 2000). Stable, normal housing is seen as a human right and the first step in integration and recovery. The service users are expected to integrate into their neighbourhoods, group activities, services, and eventually to working life (Tsemberis 2010). Integration is demonstrated as a crucial element in moving out of homelessness. HF tries to enhance community integration by scattered housing and offering intensive 
FSSs (Tsemberis \& Eisenberg 2000, Johnson et al. 2011). As Tsemberis (2010, p. 84) states: 'A [home] visit starts in the home and ends up in the community'.

As noted by Nemiroff et al. (2011, p. 1004), homelessness refers not only to a loss of housing but also disaffiliation from the community. Researchers commonly share the view that the HF model is successful and promising in moving mental health and substance abuse service users into ordinary housing and sustaining them in that housing, but it is less promising in promoting integration (e.g. McNaughton \& Atherton 2011, Pleace 2011). Persons with mental health difficulties report fairly low or moderate levels of community integration (Kaplan et al. 2012, Moriarty et al. 2012). A number of qualitative studies have reported social isolation and lack of a sense of belonging to the community among HF service users (Johnson et al. 2012, Johnsen \& Fitzpatrick 2012, 2013, Benjaminsen 2013, Busch-Geertsema 2013). It seems that it is more straightforward to resolve shortage of housing than create a position of a valued member and supportive relations in the community.

For people with homelessness, mental health and substance abuse difficulties integration into neighbourhoods and larger communities might be extremely challenging (Tsai et al. 2012). Other citizens such as employees, relatives and neighbours can display various negative attitudes towards them, ranging from prejudices to fears of real trouble or odd behaviour (Achieving the Promise 2003, Rogers \& Pilgrim 2003, Schulze \& Angermeyer 2003, Busch-Geertsema 2013). This kind of stigmatization is seen to hinder integration in many ways (Prince \& Prince 2002, Farone 2006, Harris et al. 2014). For example, internalized stigma correlates significantly with reduced activity, suggesting that changing self-stigmatizing beliefs can act as an aid to integration (Moriarty et al. 2012). 
The HF model is consistent with the mental health recovery movement in the English-speaking world (Achieving the Promise 2003, Slade 2010). In Europe the recovery movement has not yet been that influential (Slade 2010). Yet recovery through integration is an important trend both at the wider policy level and in the HF model. Recovery (like integration) is a heterogeneous and complex term (Ridgeway \& Zipple 1990, Hunt \& Stein 2012). It has community-based aspects (Smith 2000, Ochocka et al. 2005), which stress the importance of social resources, such as meaningful activities and support in promoting recovery and community integration as a pivotal prerequest and outcome of recovery. As defined in the often cited Achieving the Promise: Transforming Mental Health Care in America (2003, p. 13), 'recovery refers to the process in which people are able to live, work, learn, and participate fully in their communities'.

\section{Research setting, data and ethics}

Citizens with mental difficulties are often at risk of losing their housing and are thus in need of housing support services. Our research settings, two FSSs located in a large Finnish city, aim to meet this need. Both FSSs are managed by local mental health organizations, under a contract from the local municipality. One organization was founded in the 1970s and the other in the 1990s, to offer an alternative service to hospital treatment that is a user led and community based. The services users (in total 90) live in rented apartments scattered around the city. The home visit is the basic working method in both FSSs. The home visits' frequency is 1-3 times a week. The service is planned to be fixed-term, from 2 to 24 months. The service users are mostly young adults in a good enough condition to be able to live independently with the support of services. FSSs share many HF principles, such as scattered housing, intensive off-site support and service user choice (Tsemberis 2010). Support is delivered by by mental health nurses, practical nurses and bachelors of social services (in the two FSSs of this study there are 16 practitioners in total). So, both social and health 
care orientations are present in the FSSs' working practices.

Our data contains all 24 audio-recorded and transcribed home visits that we were able to gather during the field work period in 2011 and 2012. Home visits are 'naturally occurring' meaning that the visits were not made for the purposes of this study (Hall et al. 2014). In other words the practitioners conducted these home visits as part of their normal everyday work. The lengths of the recordings vary between 22 and 47 minutes. Home visits were usually done by one or two practitioners. However, in six of the visits also the researcher was present as a silent observer, as the research consents required clarification and signatures. When comparing the contents of the visits without or with the researcher, there are no significant differences. The contents typically cover the following themes: everyday skills, daily and weekly rhythm, illness management, relationships and medication.

The practitioners and the service users in both FSSs were expressly told that participation was voluntary and confidential and that they could withdraw their consent at any stage. They were given a written information sheet about the research. Each service user completed a consent form before the data collection commenced. The research ethics committee of the university, whose ethics the research is based on, gave a statement of approval in 2011. The study was conducted by following the guidelines on research ethics by the Finnish Advisory Board on Research Integrity and Academy of Finland (Ethical Guidelines 2014)

\section{Data analysis: community work in action}

The starting point of the analysis is that in service user-practitioner interaction the participants give meanings to the community integration and make decisions about how it should be enhanced in each individual case. We call this activity community integration work in action. By 'in action' we mean 
that community integration is work done in interaction with the services users in a particular context. It also refers to the methodology used in the analysis of the data, namely micro-sociological interaction research based on ethnomethodological ideas (Garfinkel 1967, 1974, Goffman 1983, Hall et al. 2014). The interaction research is developed for scrutinizing the 'members' methods' and 'interaction order' i.e. the ways people in interaction make sense and negotiate about social and normative realities of ordinary life (in this case integration). We chose the research orientation because it enables us to study integration as it is discussed and constructed jointly by the service users and the practitioners during their mutual encounters. We did not want to study integration for example from the stakeholders' interview accounts. Concistent with the methodology, we ask the following questions:

1) How is community integration talked into being in the home visit interaction?

2) In what ways are community integration difficulties tackled in the home visit interaction?

3) How do service users and practitioners respond to community integration talk?

Accordingly we analyze the ways participants define community integration, try to overcome integration difficulties and respond to integration discourse in interaction. For instance, the service users may resist or accept the practitioner's suggestion on how to overcome community integration difficulties. In practice, we conducted our analysis as follows. Firstly, we coded the data by using the ATLAS.ti 6 program on all the home visit episodes where the participants discuss and deal with community integration issues, such as service user ability to involve in social networks and communities.

Second, we focused on the sequences most commonly initiated by the practitioners that comprise talk about the problems with integration. Within these sequences the participants construct various dimensions of community integration problems. At one end is the dimension of 'getting out of the house', and at the other end is the most culturally valued dimension of integration, 'getting involved 
in working life'. The following 'Results' section is organized according to this continuum.

Third, we chose those sequences from different home visits that best illustrated community integration work in action in the continuum and put them to a detailed examination. In the detail analysis we concentrated on certain discursive devices based on ethnomethodologically informed interaction research that are widely used in the data: resistance (Hollander \& Einwohner 2004, Author 2014), positioning (Davies and Harré 1990), excuses and justifications (Scott \& Lyman 1968), delicacy (Silverman 1997, van Nijnatten \& Suoninen 2014) and advice-giving (Kadushin \& Kadushin 1997, Silverman 1997, Hall \& Slembrouck 2014). By applying these discursive devices we were able to capture how the service users and the practitioners respond and take stances in interaction, and how integration work is interactional accomplishment and bound to (skilful) management of the service user-practitioner interaction. Analyzing community integration work in action requires paying attention to the small but meaningful features of interaction (to discursive devices). Accordingly, it is not possible to scrutinise a mass of data at one time but one must concentrate on theoretically relevant illustrations (see e.g. Hall et al. 2014). Italics are used in the data extracts and in the text to indicate the most relevant points related to the research questions.

\section{Results}

\section{The first dimension: getting out of the house and inviting guests to visit}

In the following extract the practitioner $(\mathrm{P})$ assesses the service user's (S) social activities and simultaneously prompts the service user to meet other people. The service user's main difficulty seems to be to be able to get out of the house and take care of everyday matters independently. 


\section{Extract 1}

P: How about going to the grocery store or things like that? Have you visited any store with [boyfriend's name] or a flea market, to be around other people?

S: Last weekend we did go somewhere. [Boyfriend's name] has been working quite a lot, or he has repaired cars, so he has dropped by somewhere on the way home.

P: Have you had any energy to keep in contact with friends?

S: Through the internet. Because it's easy.

P: Yes, but you haven't visited anyone or invited anyone to your place?

S: No. You can't really invite anyone here.

P: So did you consider that if you could change the room and the arrangements, you could then do that?

The practitioner uses a question format for both getting a picture of the service user's activities that might strengthen integration and encouraging her (by giving advise) to get out of the house, keep in touch with friends and invite them over. The preferred integration is defined as going out to public venues and seeing people face to face. In turn the service user justifies and excuses the lack of integration efforts: there has been no need (or possibility) to get out of the house, and the apartment is in such a condition that you could not invite anyone over. The practitioner addressed this difficulty. She gives advice and marks the (lack of) progress in integration as a delicate issue by using the question format instead of direct assessments ('Have you had any energy to keep in contact with friends?'). As an integration method the practitioner tries to encourage the service user to be active and make changes in the home environment that would allow her to have contact with other people. Thus she takes the position of a supporter who is interested in whether, and in what ways, the service user has been able to integrate into the community. The service user's justifications and excuses may 
also be interpreted as resistance towards the underlining expectations that she ought to be more active and social in her everyday life.

\section{The second dimension: engaging with neighbours}

The service user has told to the practitioner that she is going to get a warning from the housing company for causing disorder at night-time. She had, for example, rung the neighbouring man's door and had confessed her love for him.

\section{Extract 2}

S: Yes, at least to respect the night-time silence,yes.

P1: The specified times [of silence in the housing company's] rules are important so that everyone can sleep.

P2: Yes.

S: You have to be careful with these men. I now realize that they're not that balanced after all, when I've had relationships.

P2: And no matter how balanced they are, it can still be very confusing, that sort of [behaviour].

S: Yeah. It can be in some sense.

P2: That kind of straightforward action.

S: If they are physically healthy and willing, but the psychological side just goes slower for them.

P2: So I think that it's not appropriate for anyone to shout from the balcony or wear too few clothes, for example.

S: No, I just have to come up with some hobby. I have to figure out something to replace that. P2: Some other hobby. 
The practitioners (P1 and $\mathrm{P} 2)$ stress the importance of complying with the prevailing rules. They give straightforward advice about what the service user should not do as a resident. On the basis of these instructions and notifications it can be interpreted that community integration is defined as a certain way of behaving with neighbours and as a suitable way of being in contact with them. As an excuse the client puts the blame for her unsuitable behaviour on the man's unbalanced mental condition. This excuse indicates that the service user is positioning herself as the misunderstood one. Yet she accepts the interpretation that the situation is problematic. Her solution to the integration problem is to get a new activity to replace her efforts to get attention from men. The practitioners support this reasoning and, while doing so, the distracting behaviour becomes defined in the interaction as a hobby that needs to be replaced with a new, socially acceptable one. The practitioners set boundaries to the service user's behaviour and take the positions of 'guardians'.

\section{The third dimension: participating in service users' group activities}

At the FSSs it is stressed that each service user should attend to agreed and meaningful day activities, such as the Clubhouse, the community centre and workshops. Often the service users find it difficult to go to these kinds of activities, as can be seen in the next extract.

\section{Extract 3}

P: Were you at the Clubhouse as usual on Thursday and Friday?

S: I was away on Friday.

P: Ok. 
S: No, I did not go on Thursday and Friday because it felt a bit difficult for me to leave home and go there. On Friday I said that I was ill, although that wasn't quite true, but it just felt difficult to leave home and go there. Yesterday I was away because I tried to get an appointment at the health centre, and on Thursday I had to be away because I had to take [name of the dog] to the vet. (irrelevant talk cut out)

P: Yeah, I thought whether you still can, whether you could have, could you have considered that on Thursday morning you could have contacted us by [name of the video call application]. Would that kind of a cheering-up phone call have been helpful to you?

S: I mean, I just had the thought that, I thought that I really just didn't, I wasn't enthusiastic about the idea at all. (irrelevant talk cut out)

P: What did you think about, if there at the Clubhouse, I don't know, this is just an idea I'm putting out there, but I wonder whether it would be possible with you. Since you go there on Mondays, you could plan it somehow in advance so that you would know already on Monday about what will happen on Thursday.

S: That could be quite nice.

The practitioner uses a question format for getting a view on the user's participation frequency at the Clubhouse. From the question it can be read that the preferred form of integration is regular attendance in some service user group activity. The service user gives excuses for her non-attendance. The practitioner tries to find ways to overcome the barriers to participation. Thus the means to promote integration is for the service user to contact the practitioner at the time of difficulties (a video call) and planning group activities better (in advance). The practitioner gives her advice in a tentative and delicate manner. She takes the position of an advice-giver and a 'trainer' and at the same time positions the service user as the one knowing best what could make it easier for her to participate in day activities. Her focus is on suggesting what the service user could in practice do to avoid non- 
attendance in the future. At first the service user resists and downplays the suggestion but at the end of the extract she supports the second proposal.

\section{The fourth dimension: getting along with one's close ones}

In the extract the service user talks about the difficulties in his mother-son relationship. He reports that he has tried to stop drinking yet his mother is still anxious about his substance abuse and asks and talks about it constantly.

\section{Extract 4}

S: It's straining [the mother worrying and making accusations about substance abuse]. I have tried to say do not strain me, that I just experience and feel it so strongly.

$\mathrm{P}$ : On the other hand, what do you think if your mother is worried about your substance abuse, and you have relapsed many times now, so has that been helpful, that you are using it as a medication for it, so that it just continues from there? Your mother is worried about your substance abuse and you're reacting to it by using intoxicants even more?

S: Yeah, I just take them, yeah.

P: But does the problem get solved that way?

S: It helps for a moment.

$\mathrm{P}$ : But it would be good if we tried to arrange something like [a meeting], what do you think [name of $\mathrm{S}]$ ?

S: Well that's why I wanted to talk to you, about that, if there's anything.

P: Some kind of meeting where your mother would be present. We would discuss the matter together, how we could act in a way that [the problem becomes solved], because it's entirely normal, this is the 
same phenomenon where parents are usually always worried about their child and this kind of concern comes naturally. (irrelevant talk cut out)

P: Yeah, some common rules, it's good to think about what we could maybe do, to make both of you feel a bit better, so of course you have to understand it, your mother's fussing, it's normal.

S: [gives a short laugh] True.

The assumptions in this conversation imply that successful community integration and recovery calls for functioning (not stressful) relationships between the service user and his close ones. Integration is defined as an ability to stay sober and get along with people who are meaningful. Relationship difficulties are used for explaining and excusing the service user's relapses. The practitioner and the service user construct jointly causal relations between substance abuse and relationship problems. The practitioner does integration work by questioning the service user's reasoning and patterns of action, explaining to the service user his mother's position as well as suggesting a joint meeting for setting common rules among the stakeholders. Thus the practitioner acts as a mediator, advisor and interpreter between the service user and the significant other. The service user accepts this kind of integration work and is active in constructing the integration and recovery problem at hand.

\section{The fifth dimension: getting involved in working life}

In the extract the practitioner asks the service user how actively he has taken part in the mental health organization's service user group activities. One of the group's aims is to help the participants to make future plans. In the conversation the service user and the practitioner continue making plans, setting the next steps for the future transition to working life. 


\section{Extract 5}

P: Yeah, you see I was just thinking about the fact that you don't really know what kind of occupation you would like to have. I thought, what if you make an appointment for a vocational psychologist through the employment services?

S: I have been to an appointment like that sometime after secondary school, they put me in practical training at a construction firm. That's what I've studied.

P: I mean that it would be a different situation now for you to think about it and maybe you would now be more ready to think about it. Or now of course it's a different situation. There you could think about it, the kinds of options you could consider.

S: I suppose I could go there to have a discussion.

P: I thought about the joint application procedure [for schools and polytechnics in Finland]. You could make a phone call and ask how long it takes, how long you would have to wait for an appointment. There can be a long queue for that. I thought that it would be quite good if you feel like it, it could be a good thing, so you could ask about that next week.

S: Yeah, I will try to remember that.

P: I thought, what if I look up the phone number from the employment services and then you could make the appointment? I could call you next week, for instance.

S: Yeah.

The practitioner perceives the integration (problem) to be related to the service user being (un)aware of his own field and having no plans for educating himself and entering working life in the future. Accordingly the integration work focuses on prompting and supporting the service user to arrange an appointment with a vocational psychologist. The practitioner takes the position of a care coordinator and tries to offer (in a delicate and questioning way) an additional service to the service 
user in order to facilitate the integration process. The service user hesitates and resists in a subtle manner, yet also agrees with the practitioner's suggestion.

\section{Discussion and conclusion}

In this article we have studied community integration problems and the means to overcome them as they are talked into being and tackled at the home visit encounters in the FSSs. The results on community integration work in service user-practitioner interaction complement the literature in this research area. In the mental health and HF literature the importance of integration is often stated in general and in an unproblematic manner (e.g. Tsemberis 2010, Johnson et al. 2012), but when looking at community integration work in action it is revealed how complex and sensitive achievement community integration is in discourse and in practice. The practitioners need to manage many positions and discursive devices as well as the service users' responses and resistance. From the service users' point of view integration requires multiple and often demanding social skills to interact with various people in different settings.

Previous research emphasizes service systems' and practitioners' responsibility in advancing integration of vulnerable citizens (Abbott \& McConkey 2006, Carnaby et al. 2011; Asselt-Goverts et

al. 2014). Yet, as our analysis demonstrates, service users are directed to make changes in their ways of doing and thinking in order to adjust better to common life in the community. Although the practitioners do this directing in subtle and respectful ways, the service users often resist the expectations and demands to make efforts towards being an integrated citizens. The analysis makes visible how service users are made responsible for their own integration, much less (if at all) is talked about how the community could be made more inclusive. This comes back to the individualized 
definitions of integration and the tradition of individual-based working methods in mental health (Cameron 2006; Hall 2010)

A crucial element in re-thinking integration is an attitude change (Abbott \& McConkey 2006): the acceptance of differences, an ability to construct 'others' as 'us' and to be critical toward normative cultural expectations of integration. Normativity is also embedded in the dimensions of integration presented in the article (getting out of the house; participating in group activities and getting along with ones' close ones and involving in working life). They are are based on the assumptions of what vulnerable citizens are excluded from: social relations and activities, labour market, economy, society, culture and citizenship, etc. (Cameron 2006). Therefore there is the risk that integration discourse in mental health strengthens the categorical divisions between 'us' and 'others', and sets responsibilities only for the 'others' to becomes like 'us'. As Cameron (2006: 397) states

The way the social exclusion debate has developed places an enormous responsibility on those considered to be excluded to resolve their own problems - they have been made responsible for their own condition as a form of social 'pathology'.

Community integration work in action is demanding for both the service users and the practitioners: how to balance normative cultural expectations and different and multiple ways to integrate so that the service users would be able adopt valued roles in the community (see also Asselt-Goverts et al. 2014). Integration is about social interaction in the community. Thus housing and recovery from mental health difficulties is not only an individual challenge but also a social challenge, our challenge.

This article has captured community integration only from a particular setting and perspective. Although we are aware of the normative load of the concept integration and wish to question it, the text might also strengthen the cultural expectations of the 'right' ways to integrate to the community. 
The results are drawn from small-scale study not allowing us to make too general conclusions. The particular institutional contexts and objectives as well as service users' and practitioners' backgrounds shape the realization of community integration work (see Aubry et al. 2013). At best the study offers conceptual tools and ideas for future research on integration challenges and for developing working methods that would increase citizenship, belonging and connectedness of vulnerable citizens in the community (Ware et al. 2007; Hall 2010). The interactive data does not provide access to the service users' (or practitioners') personal experiences concerning community integration. However, our study makes visible how community integration is discussed and tackled in front-line mental health practices, and demonstrates the usefulness of ethnomethodological approach in analysing these practices. Making these practices visible can give grounds for creating more reflective and empowering community integration work.

\section{References}

Abbott, S. \& McConkey, R. (2006) The barriers to social inclusion as perceived by people with intellectual disabilities. Journal of Intellectual Disabilities. 10 (3), 275-287.

Abdallah C., Cohen C.I., Sanchez-Almira M., Reyes P. \& Ramirez P. (2009) Community integration and associated factors among older adults with schizophrenia. Psychiatric Services 60 (12), 1642-1648.

Achieving the Promise: Transforming Mental Health Care in America. Full report. The President's New Freedom $\quad$ Commission Mental Health (2003). http://govinfo.library.unt.edu/mentalhealthcommission/reports/FinalReport/downloads/downloads.h tml (accessed on 4/3/2014) 
Anthony W.A. (1993) Recovery from mental illness: The guiding vision of the mental health service system in the 1990s. Psychosocial Rehabilitation Journal 16 (4), 11-23.

Asselt-Goverts, A.E., Embregts, P.J.C.M., Hendriks, A.H.C. \& Frielink, N. (2014) Experiences of support staff with expanding and strengthening social networks of people with mild intellectual disabilities. Journal of Community \& Applied Social Psychology 24 (2), 111-124.

Aubry, T., Flynn, R., Virley, B. \& Neri, J. (2013) Social role valorization in community mental health housing: does it contribute to the community integration and life satisfaction of people with psychiatric disabilities?. Journal of Community Psychology 41(2) pp.218

Benjaminsen, L. (2013) Rehousing homeless citizens with assertive community treatment. Experiences from an ACT-programme in Copenhagen. Housing First Europe. Local Evaluation Report. EU, Copenhagen.

Beresford P., Shamash M., Forrest V., Turner M. \& Branfield F. (2005) Developing social care: service users' vision for adult support. By the Social Care Institute for Excellence. http://www.scie.org.uk/publications/reports/report07.pdf (accessed on 4/3/2014)

Busch-Geertsema V. (2013) Housing first Europe. Final Report. EU, Bremen/Brussels.

Cameron, A. (2006) Geographies of welfare and exclusion: social inclusion and exception. Progress in Human Geography 30 (3), 396-404. 
Carling P.J. (1990) 'Major mental illness, housing, and supports: the promise of community integration'. American Psychologist 45 (8), 969-975.

Carnaby, S., Roberts, B., Lang, J. \& Nielsen, P. (2011) A flexible response: person-centred support and social inclusion for people with learning disabilities and challenging behaviour. British Journal of Learning Disabilities 39 (1), 39-45.

Cornes M., Manthorpe J., Joly L. \& O`Halloran S. (2014) Reconciling recovery, personalisation and Housing First: Integrating practice and outcome in the field of multiple exclusion homelessness. Heath \& Social Care in the Community 22 (2), 134-143.

Davies B. \& Harré R. (1990) 'Positioning: the discursive production of selves.' Journal for the Theory of Social Behavior 20 (1), 43-63.

European commission green paper. Improving the mental health of the population. Towards a strategy on mental health for the European Union (2005) Brussels: EU.

Ethical Guidelines (2014) http://www.aka.fi/en-GB/A/Funding-and-guidance/Use-offunding/Ethical-guidelines/

Farone D.W. (2006) Schizophrenia, community integration, and recovery: implications for social work practice. Social Work in Mental Health 4 (4), 21-36.

Garfinkel H. (1967) Studies in Ethnomethodology. Polity Press, Cambridge. 
Garfinkel H. (1974) The origins of the term 'ethnomethodology'. In Turner Roy (ed.) Ethnomethodology: Selected Readings. Penguin Education, Harmondsworth, 15-18.

Goffman E. (1983) The interaction order. American Sociological Review 48, 1-17.

Gulcur L., Tsemberis S., Stefancic A. \& Greenwood R.M. (2007) Community integration of adults with psychiatric disabilities and histories of homelessness. Community Mental Health Journal 43 (3), $211-228$.

Hall, E. (2010) Spaces of social inclusion and belonging for people with intellectual disabilities. Journal of Intellectual Disability Research 54(Supplement 1), 48-57.

Hall C. \& Slembrouck S. (2014) Advice-giving. In Hall C., Juhila K., Matarese M. \& van Nijnatten C., (eds). Analysing Social Work Communication. Discourse in Practice. Routledge, London, 98116.

Hall C., Juhila K., Matarese M., \& van Nijnatten C., (2014) Analysing Social Work Communication. Discourse in Practice. Routledge, London.

Harris, L.M., Matthews, L.R., Penrose-Wall, J., Alam, A. \& Jaworski, A. (2014) Perspectives on barriers to employment for job seekers with mental illness and additional substance-use problems. Health \& Social Care in the Community. 22 (1), 67-77.

Hollander J.A. \& Einwohner R.L. (2004) Conceptualizing Resistance. Sociological Forum 19 (4), 533-554. 
Hunt M.G. \& Stein C.H. (2012) Valued social roles and measuring mental health recovery: Examining the structure of the tapestry. Psychiatric Rehabilitation Journal 35 (6), 441-446.

Johnsen S. \& Fitzpatrick S. (2012) Turning Point Scotland's housing first pilot evaluation: interim report: Heriot-Watt University, Edinburgh. https://pureapps2.hw.ac.uk/portal/files/1930308/InterimReport.pdf (accessed on 4/3/2014)

Johnsen, S. \& Fitzpatrick, S. (2013) Housing first Europe: local evaluation report Glasgow housing first. EU, Housing First Europe.

Johnson G., Parkinson S. \& Parsell C. (2012) Policy shift or program drift? Implementing housing first in Australia. AHURI Final Report No 184. Australian Housing and Urban Research Institute.

Kadushin A. \& Kadushin G. (1997) The social work interview: a guide for human service professionals. Columbia University Press, New York.

Kaplan K., Salzer M. \& Brusilovskiy E. (2012) Community participation as a predictor of recoveryoriented outcomes among emerging and mature adults with mental illnesses. Psychiatric Rehabilitation Journal 35 (3), 219-229.

Loch, D. (2014) Integration as a sociological concept and national model for immigrants: scope and limits. Identities 21 (6), 623-632. 
McConkey, R. \& Collins, S. (2010) The role of support staff in promoting the social inclusion of persons with an intellectual disability. Journal of Intellectual Disability Research 54 (8), 691-700.

McNaughton N.C. \& Atherton I. (2011) Housing first: considering components for successful resettlement of homeless people with multiple needs. Housing Studies 26 (5), 767-777.

Moriarty A., Jolley S., Callanan M. \& Garety P. (2012) Understanding reduced activity in psychosis: the roles of stigma and illness appraisals. Social Psychiatry \& Psychiatric Epidemiology 47 (10), $1685-1693$.

Musterd S. \& Alan M. (2002) The spatial dimensions of urban social exclusion and integration. Final report. URBEX series, No. 22. Amsterdam, EU.

http://ec.europa.eu/research/social-sciences/pdf/finalreport/soe2ct983072-final-report.pdf (accessed on $4 / 3 / 2014$ )

Nemiroff, R., Aubry, T. \& Klodawsky, F. (2011) From homelessness to community: psychological integration of women who have experienced homelessness, Journal of Community Psychology 39 (8), 1003-1018.

Ochocka J., Nelson G. \& Janzen R. (2005) Moving forward: negotiating self and external circumstances in recovery. Psychiatric Rehabilitation Journal 28 (4), 315-322.

O'Hara A. (2007) Housing for people with mental illness: update of a report to the President's New Freedom Commission. Psychiatric Services 58, 907-913. 
Onken S.J, Craig C.M., Ridgway P., Ralph R.O. \& Cook J.A. (2007) An analysis of the definitions and elements of recovery: A review of the literature. Psychiatric Rehabilitation Journal 31 (1), 9-22.

Pleace N. (2011) The ambiguities, limits and risks of housing first from a European perspective. European Journal of Homelessness 5 (2), 113-122.

Pleace N. (2012) Housing First. FEANTSA, Belgium. http://www.feantsaresearch.org/IMG/pdf/housing_first_pleace.pdf (accessed on 4/3/2014)

Pleace N. \& Bretherton J. (2012) Will paradigm drift stop housing first from ending homelessness? Categorising and critically assessing the housing first movement from a social policy perspective. Paper given at 'Social Policy in an Unequal World' Joint annual conference of the East Asian Social Policy Research Network and the UK Social Policy Association.

http://www.york.ac.uk/media/chp/documents/2006/NPJB-EASP-SPA-2012.pdf （accessed on $8 / 1 / 2015)$

Prince P.N. \& Prince C.R. (2002) Perceived stigma and community integration among clients of assertive community treatment teams. Psychiatric Rehabilitation Journal, 25, 323-331.

Ridgeway P. \& Zipple A.M. (1990) The paradigm shift in residential services: From the linear continuum to supported housing approaches. Psychosocial Rehabilitation Journal 13 (4), 11-31.

Rogers A. \& Pilgrim D. (2003) Mental health and inequality. Palgrave MacMillan, New York. 
Saunders, P. (2013) Reflections on the concept of social exclusion and the Australian social inclusion agenda. Social Policy \& Administration 47 (6), 692-708.

Schinkel, W. (2013) The imagination of society' in measurements of immigrant integration. Ethnic and Racial Studies 36 (7), 1142-1161.

Schulze B. \& Angermeyer M.C. (2003) Subjective experience of stigma. A focus group study of schizophrenic patients, their relatives and mental health professionals. Social Science \& Medicine 56 (2), 299-312.

Scott M.B. \& Lyman S.M. (1968) ‘Accounts’. American Sociological Review 33 (1), 46-62.

Silverman D. (1997) Discourses of counselling: HIV counselling as social interaction. Sage, London.

Slade M. (2010) Measuring recovery in mental health services. The Israel Journal of Psychiatry and Related Sciences 47 (3), 206-212.

Smith M.K. (2000) Recovery from a severe psychiatric disability: Findings of a qualitative study. Psychiatric Rehabilitation Journal 24 (2), 149-158.

Stancliffe, R.J. (2014) Inclusion of adults with disability in Australia: outcomes, legislation and issues. International Journal of Inclusive Education 18 (10), 1053-1063. 
Stein C.H. \& Wemmerus V.A. (2001) Searching for a normal life: Personal accounts of adults with schizophrenia, their parents and well-Siblings. American Journal of Community Psychology 29 (5), $725-746$.

Tsai J., Desai R. \& Rosenheck R. (2012) Social integration of people with severe mental illness: Relationships between symptom severity, professional assistance, and natural support. Journal of Behavioral Health Services \& Research 39 (2), 144-157.

Tsemberis S. (2010) Housing first. The pathways model to end homelessness for people with mental Illness and Addiction. Hazelden, Minnesota.

Tsemberis S. \& Eisenberg R.F. (2000) Pathways to housing: Supported housing for street dwelling homeless individuals with psychiatric disabilities. Psychiatric Services 51, 487-493.

van Nijnatten C. \& Suoninen E. (2014) Delicacy. In Hall C., Juhila K., Matarese M. \& van Nijnatten C., (eds.). Analysing Social Work Communication. Discourse in Practice. Routledge, London, 136153.

Ware, N., Hopper, K., Tuggenberg, T., Dickey, B. \& Fisher, D. (2007) Connectedness and citizenship: redefining social integration. Psychiatric Services 58(4), 469-474.

Wieviorka, M. (2014) A critique of integration. Identities 21 (6), 633-641.

Wong Y.L. \& Solomon P.L. (2002) Community integration of persons with psychiatric disabilities in supportive independent housing: A conceptual model and methodological 
considerations. Mental Health Services Research 1, 13-28.

Yanos P.T., Barrow, S.M. \& Tsemberis, S. (2004) Community integration in the early phase of housing among homeless persons: Successes and challenges. Community Mental Health Journal 40 (2), 133-150.

Yanos, P.T., Stefanic, A. \& Tsemberis, S. (2011) Psychological community integration among people with psychiatric disabilities and nondisabled community members. Journal of Community Psychology (39) 4, 390-411. 